\title{
Preliminary study for the development of potent hydrogels for local drug delivery applications
}

\author{
Ece Özcan Bülbül ${ }^{1}$, Panoraia I. Siafaka ${ }^{2}$, Gökçe Mutlư ${ }^{3}$, Neslihan Üstündağ Okur ${ }^{3 *}$ \\ ${ }^{1}$ Department of Pharmaceutical Technology, Faculty of Pharmacy, İstinye University, İstanbul, Turkey \\ ${ }^{2}$ School of Health Studies, KES College, Nicosia, Cyprus \\ ${ }^{3}$ Department of Pharmaceutical Technology, Faculty of Pharmacy, University of Health Sciences, İstanbul, Turkey
}

\begin{tabular}{|c|c|}
\hline \multicolumn{2}{|c|}{ ARTICLE INFC } \\
\hline \multicolumn{2}{|c|}{ Article history: } \\
\hline Received & 09 Jan 2021 \\
\hline Revised & 11 Jun 2021 \\
\hline Accepted & 11 Jun 2021 \\
\hline Online & 09 Sep 2021 \\
\hline Published & - \\
\hline \multicolumn{2}{|l|}{ Keywords: } \\
\hline \multicolumn{2}{|l|}{ Carbopol } \\
\hline \multicolumn{2}{|c|}{ Carboxymethyl cellulose } \\
\hline \multicolumn{2}{|c|}{ Hydrogels } \\
\hline \multicolumn{2}{|c|}{ Local drug delivery } \\
\hline \multicolumn{2}{|c|}{ Mechanical activity } \\
\hline \multicolumn{2}{|c|}{$\begin{array}{l}{ }^{*} \text { Corresponding author: } \\
\text { neslihanustundag@yahoo.com }\end{array}$} \\
\hline
\end{tabular}

\begin{abstract}
A B S T R A C T
Currently, design and development of formulations for the oral cavity and local application is a rather challenging process since the components should be non-irritant and provide relief. Hydrogels-based drug delivery systems have been proposed as suitable candidates for oral mucosal (eg, buccal, sublingual, palatal, gingival) and local (dermal) drug delivery (eg, wound dressings). Herein, the hydrogels were prepared by Carbopol 934, Sodium carboxymethyl cellulose as well as their combination blends to develop efficient hydrogels with tunable activities. The hydrogels were characterized in terms of tensile testing, and physicochemical properties ( $\mathrm{pH}$, clarity). Fourier-Transformed Infrared Spectroscopy (FT-IR) was used to evaluate any possible interactions between the components or any newly developed by-products which can lead to toxicity. The F2/F5 formulation, $\mathrm{pH}(5.86 \pm 0.084)$, viscosity (13305 \pm 1209$)$, firmness (39.92 \pm 0.77$)$, consistency (356.27 \pm 9.01$)$, cohesiveness $(-28.58 \pm 0.81)$, and work of cohesion $(-231.31 \pm 15.02)$ values were found to be the most suitable formulation. According to the results and the use of biocompatible ingredients, the prepared hydrogels present promising characteristics being suitable candidates for mouth application. Future studies will involve the loading of active molecules and studying their properties.
\end{abstract}

This is an open-access article licensed under the Creative Commons Attribution 4.0 International License (CC-BY). (⿻) ) EY

\section{INTRODUCTION}

Conventional formulations such as pills, tablets, capsules, etc. are suitable for specific diseases since mouth diseases and wounds require the topical application of the drug in the affected area. Moreover, conventional drug delivery systems have shown reduced therapeutic efficacy, require repeatable doses to achieve the therapeutic outcome diminishing patient compliance and resulting in possible toxicity [1]. Thus, the preparation of innovative formulations that can achieve controlled drug release and reduced toxicity is a very significant field for pharmaceutical technologists. Local drug delivery is suitable for diseases of the mouth or wounds since it acts in the desired tissue lowering the possibility of adverse effects [2-4].

There are various reported disorders of the oral cavity such as ulcers (malignant, traumatic), sores, stomatitis, oral infections from pathogens (fungi, bacteria viruses) [5-7] that should be treated to avoid any harmful events. Recurrent aphthous stomatitis is among the most common mouth diseases which affect many people; it is a painful condition described as sores of grayish-white pseudomembrane surrounded by an erythematous halo [8,9]. It has been reported that its pathogenesis is unknown and thus aphthous stomatitis treatment options mostly aim to reduce the symptoms and their duration. Various drugs have been proposed for therapeutic management as antibacterial, antiacidic, and antineoplastic agents as well as anti-inflammatory and immunomodulatory agents $[8,10,11]$. Semisolid, liquid and solid formulations are the most commonly used types of drug carriers designed for the oral cavity; nonetheless, they present low retention time requiring frequent installation. Thus, the gelling systems (in situ gels, hydrogels, etc.) are proposed as efficient carriers for oral cavity disorders since their gelling capacity can prevent them from being swallowed $[3,12,13]$.

Another drug delivery route that belongs to local drug delivery is that of wound or dermal delivery $[14,15]$. Wounds are derived from injury of the skin that normally healed. However, if the wound healing process is impaired for any reason, the wound will heal slowly or not healed at all. Chronic wounds can be colonized by fungi, bacteria, or virus resulting in medical health conditions as bacteremia, or sepsis that can be fatal $[16,17]$. Wound management could cost massive expenses to health systems. Consequently, medical practitioners carefully examine wounds to provide the most effective wound dressing [18,19]. Wound dressings are applied on the open wound while various dressing types 
have been identified. For example, foam, gels, alginate, collagen, and other dressings are used in clinical practice [20]. Other innovative dressings might include nanoparticles, natural plants, drugs, or other biological agents that can accelerate the wound healing progress [16,21,22]. Hydrogelbased membranes are widely applied as wound delivery carriers [23,24]. The use of topical dressings derived from polymers with hydrogel properties has been studied as a prophylactic procedure to prevent systemic infection $[15,25]$.

Gel-based systems i.e. hydrogels have been proposed for both local and systemic treatment applications due to their biocompatibility and tunable properties such as controlled release, biodegradability [26]. Hydrogels are comprised of a network of cross-linked hydrophilic chain polymer that is hydrophilic that can find as a colloidal gel in water. Water acts as the dispersion medium and should constitute at least $10 \%$ of the total volume so as the material to be a hydrogel [27]. The hydrogels can undergo a sol-gel phase or volume phase transition due to physical and chemical stimuli response. More specifically, temperature, electric and magnetic fields, solvent composition, pressure are physical stimuli, whereas $\mathrm{pH}$ and ion changes are chemical stimuli [28 -31]. This transition is mostly reversible since as soon as the trigger factor removes the hydrogels can return to their initial form [27]. Various synthetic and natural macromolecules have been employed for hydrogel preparation. Carbopol (CP) is a high molecular weight, hydrophilic, and cross-linked polyacrylic acid polymer which can become swollen when contacted with water [32]. CP-based hydrogels have been reported as potential systems for oral mucoadhesive drug delivery [33,34]. Carboxymethylcellulose (CMC) is an anionic hydrophilic cellulose derivative bounding with carboxymethyl groups. CMC is used in syrup and sauce formulations to increase viscosity while it has been widely found in drug delivery and tissue engineering applications [35-37]. CMC is mostly used as its sodium salt (Na-CMC). In this study, we have conducted preliminary work on the development of potent hydrogels for potential local drug delivery applications. Two polymers (CP and Na-CMC) were chosen for the preparation of hydrogels which can potentially be applied as local formulations considering their biocompatibility and toxicological safety profile. Also, the pure hydrogels blended to form mixtures with different mechanical properties and $\mathrm{pH}$ values.

\section{MATERIALS AND METHODS}

\subsection{Materials}

Carbopol (CP) 934 and sodium carboxymethyl cellulose (Na-CMC) were purchased from Doğa İlac, Turkey. In the study, distilled aqueous media was applied. The other chemical reagents and solvents were of analytical grade.

\subsection{Methods}

\subsubsection{Preparation of the hydrogels}

The preparation of gel formulations was conducted using different concentrations $(0.5 \%, 1.0 \%, 1.5 \%, \mathrm{w} / \mathrm{w})$ of CP 934 and $\mathrm{Na}-\mathrm{CMC}$. The polymers and the water were added to the beaker and mixed with magnetic stirring for 3 hours. F1/F4, F2/F5, and F3/F6 formulations (blended hydrogels) were prepared by mixing $50 \% \mathrm{w} / \mathrm{w}$ from each formulation and magnetically stirred for 3 hours. Table 1 depicts the composition of the developed hydrogels.

Table 1. Composition of the developed hydrogels

\begin{tabular}{lccc}
\hline Code & \multicolumn{3}{c}{ Concentration \% (w/w) } \\
\cline { 2 - 4 } & $\begin{array}{c}\text { Carbopol } \\
\text { (CP) 934 }\end{array}$ & $\begin{array}{c}\text { Carboxymethyl-cellulose } \\
\text { (Na-CMC) }\end{array}$ & Water \\
\hline F1 & 0.5 & - & 99.5 \\
F2 & 1.0 & - & 99.0 \\
F3 & 1.5 & - & 98.5 \\
F4 & - & 0.5 & 99.5 \\
F5 & - & 1.0 & 99.0 \\
F6 & - & 1.5 & 98.5 \\
\hline
\end{tabular}

\subsubsection{FT-IR spectroscopy analysis}

The prepared hydrogels were subjected to FT-IR analysis using ATR-FTIR (Attenuated Total Reflection Fourier Transform Infrared) spectroscopy (FTIR-spectrometer FTIR2000 (Perkin Elmer, USA). FT-IR spectra were recorded over a spectral region from 4000 to $400 \mathrm{~cm}^{-1}$ to ascribe the function groups of the hydrogel samples [38].

\subsubsection{Appearance}

The developed hydrogels were inspected visually for their clarity, color, and particle content.

\subsection{4. pH measurement}

The $\mathrm{pH}$ values of the hydrogel formulations were determined by a digital pH-meter (Mettler Toledo, Switzerland). The electrode was inserted into the hydrogel and constant value was noted. The measurements were repeated three times at $25 \pm 0.5^{\circ} \mathrm{C}$.

\subsubsection{Viscosity}

The viscosities of hydrogel formulations were measured using Brookfield RV-10 viscometer at $25^{\circ} \mathrm{C}$ (Brookfield, USA).

\subsubsection{Mechanical properties}

The mechanical properties tested using a softwarecontrolled penetrometer TA-XT Plus Texture Analyzer (Stable Micro Systems, Surrey, UK) equipped with a $5 \mathrm{~kg}$ load cell. Each formulation $(50 \mathrm{~g})$ was transferred to a 100 $\mathrm{mL}$ beaker and left in an ultrasonic bath for about one hour to remove air bubbles. In the study using a Perspex probe of 10 $\mathrm{mm}$ diameter; the test was carried out at a pretest speed of 2 $\mathrm{mm} / \mathrm{s}$, post-test speed of $2 \mathrm{~mm} / \mathrm{s}$, test speed of $2 \mathrm{~mm} / \mathrm{s}$, trigger force of $0.001 \mathrm{~N}$, compression depth to the gel in each operation of $10 \mathrm{~cm}$, delay period between two compressions of $10 \mathrm{~s}$. The mechanical properties of all hydrogels were calculated using the Texture Exponent 4.0.4.0 software package of the instrument $[25,26]$. All experiments were repeated three times at $25 \pm 0.5^{\circ} \mathrm{C}$ [39-41].

\section{RESULTS AND DISCUSSION}

$\mathrm{CP}$ and $\mathrm{CMC}$ were chosen to prepare hydrogel formulations due to their hydrophilicity, biocompatibilitybiodegradability as well as mucoadhesion properties $[31,42,43]$. Throughout the literature, various concentrations of the polymers were used for the preparation of hydrogels; herein, we decide to choose three different concentrations 
$(0.5 \%, 1 \%, 1.5 \%, \mathrm{w} / \mathrm{w})$ for pure hydrogels while the blends of hydrogels were developed using $50 \%$ of the pure hydrogels. The blending procedure has been identified as a suitable process for obtaining formulations with different properties. Most of the physicochemical values of the blends were between the initial values.

\subsection{FT-IR Spectroscopy Analysis}

The evaluation of pharmaceutical formulations using FTIR spectroscopy is a very significant process since FTIR can show possible interactions between the components. Such interactions can affect the release process, physicochemical even in vivo behavior of the formulations. Herein, the hydrogels follow the typical spectrum of their original compositions. Two different polymers known to develop hydrogels when contacted with water were used, herein: Na-CMC and CP 934. Na-CMC is the sodium salt of carboxymethyl cellulose while CP 934 is a high molecular weight of cross-linked polyacrylic acid.
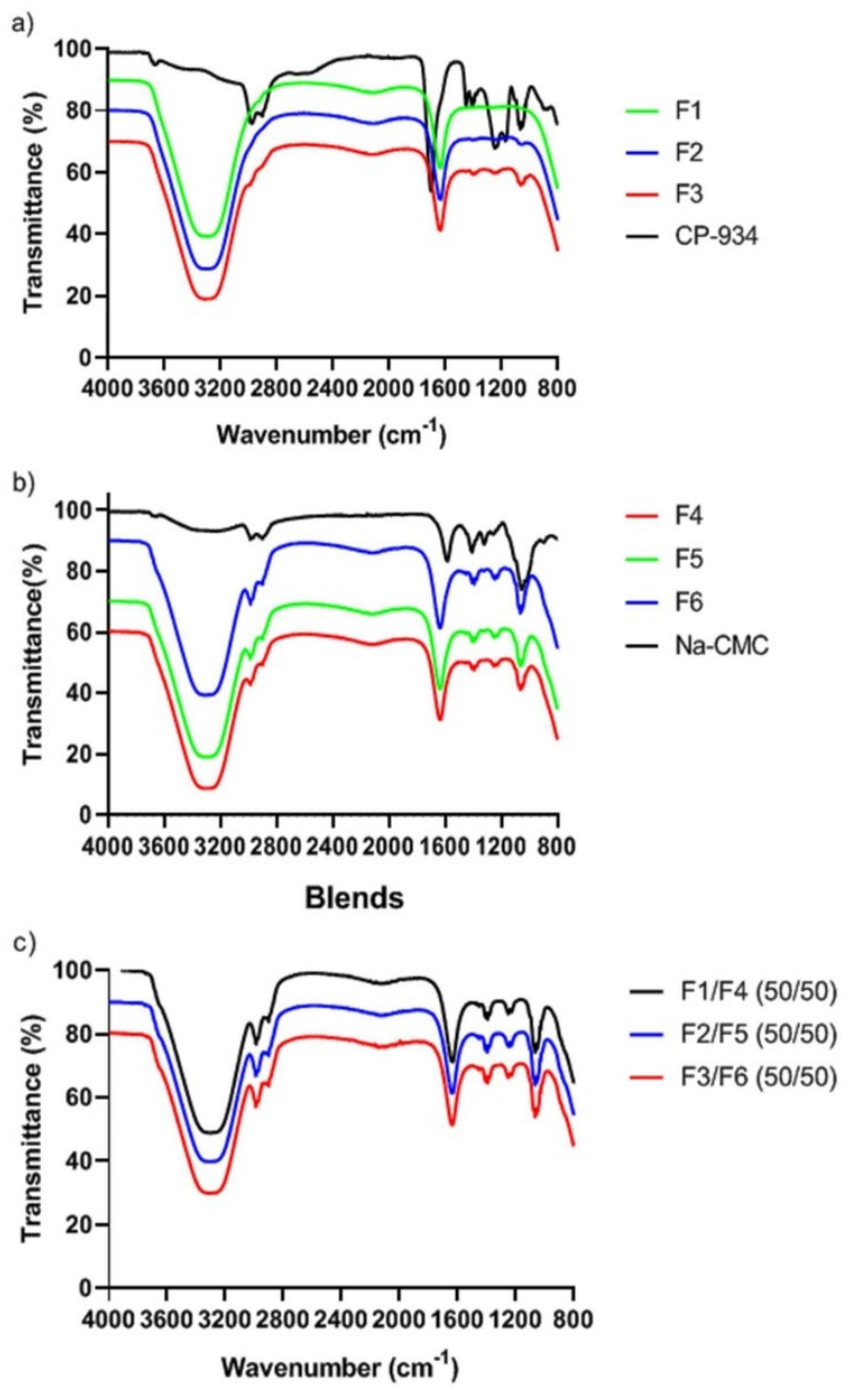

Figure 1. FT-IR spectroscopy analysis of (a) F1, F2, F3 hydrogels and pure CP 934; (b) F4, F5, F6 and pure Na-CMC; (c) blends between $F 1$ and $F 4, F 2$ and $F 5$ as well as $F 3$ and $F 6$

Figure 1a shows the spectra of CP 934 and the hydrogels of different concentrations of CP 934 (F1, F2, and F3). As was expected, the F1, F2, F3 formulations mostly follow the spectrum of pure CP 934. Pure CP 934 depicts at 3000-2950 $\mathrm{cm}^{-1}$ the $\mathrm{OH}$ stretching vibration whereas at $1717 \mathrm{~cm}^{-1}$ was assigned the carbonyl $\mathrm{C}=\mathrm{O}$ stretching band. Moreover, the band at $1237 \mathrm{~cm}^{-1}$ represents the $\mathrm{C}-\mathrm{O}-\mathrm{C}$ peak for acrylates $[25,44]$. The hydrogels present a broad sharp band at 3300 $\mathrm{cm}^{-1}$ due to water content. Figure $\mathbf{1 b}$ exhibits the FTIR spectrum of carboxymethyl cellulose sodium salt and F4, F5, F6 Na-CMC spectrum demonstrated a band at $2920 \mathrm{~cm}^{-1}$ representing the $\mathrm{C}-\mathrm{H}$ anti-symmetrical stretching while at 1600 and $1408 \mathrm{~cm}^{-1}$ the bands due to carboxylate groups stretching vibrations (symmetric and asymmetric) are seen. At $3400 \mathrm{~cm}^{-1}$ the presence of $\mathrm{OH}$ band is also depicted. In the case of the formulations, F4, F5, and F6 represent a similar spectrum with $\mathrm{Na}-\mathrm{CMC}$ with the only difference that the band at 3400 is sharp due to water presence [45]. It can be said that the prepared hydrogels did not exhibit any new peaks indicating stability and compatibility. Figure 1c depicts the spectra of the blends between F1 and F4, F2 and F5, F3, and F6. It is well reported that blends are widely used in pharmaceutical technology since they can be useful for enhancing the properties of each component. Also, the blending can differentiate drug release and in vitro/in vivo performance of the formulation (Figure 1c) $[46,47]$. Herein, $50 \%$ of each hydrogel was blended with another hydrogel to produce blends of them and examine their mechanical properties. The blends did not exhibit any interesting differences or any new peaks. The blends mostly followed the spectra of both excipients while the absence of new peaks indicates that new bonds were not depicted. Thus, the prepared blends would be stable and by-products being harmful to the oral mucosa or skin were not detected.

\subsection{Appearance and $\mathrm{pH}$ Measurement}

All gels were described as transparent when visually checked. Table 2 summarizes the $\mathrm{pH}$ and clarity values of the hydrogels. As was expected, the formulations developed by $\mathrm{CP}(\mathrm{F} 1, \mathrm{~F} 2, \mathrm{~F} 3)$ presented $\mathrm{pH}$ values around $\mathrm{pH} 4$ and the Na-CMC (F4, F5, F6) were around $\mathrm{pH} 8$.

Table 2. $p H$ and clarity values of the hydrogels and their blends

\begin{tabular}{lcc}
\hline Code & pH & Clarity \\
\hline F1 & $4.45 \pm 0.091$ & Transparent \\
F2 & $4.15 \pm 0.042$ & Transparent \\
F3 & $3.78 \pm 0.021$ & Transparent \\
F4 & $8.18 \pm 0.106$ & Transparent \\
F5 & $8.42 \pm 0.007$ & Transparent \\
F6 & $8.38 \pm 0.247$ & Transparent \\
F1/F4 (50/50) & $5.94 \pm 0.007$ & Transparent \\
F2/F5 (50/50) & $5.86 \pm 0.084$ & Transparent \\
F3/F6 (50/50) & $6.05 \pm 0.120$ & Transparent \\
\hline
\end{tabular}

The blends of the hydrogels exhibited higher $\mathrm{pH}$ values than $\mathrm{CP}$-based hydrogels and lower than $\mathrm{Na}-\mathrm{CMC}$ values. The $\mathrm{pH}$ of the blends was found between the values of initial polymers. F1, F2, and F3 have acidic $\mathrm{pH}$ values and F4, F5, F6 have basic $\mathrm{pH}$ values. Normal $\mathrm{pH}$ value of oral cavity is $6.8[48,49]$. The normal skin $\mathrm{pH}$ is 5.0-5.5 [50], but depending on the area, it may vary [51]. Generally, the $\mathrm{pH}$ values of the blended hydrogels were similar to that of human skin $\mathrm{pH}$ and oral cavity $\mathrm{pH}$ indicating that the hydrogels could be applied as topical wound dressings and oral cavity applications. So F1/F4, F2/F5, and F3/F6 (blended hydrogels) were more appropriate for local application due to their better $\mathrm{pH}$ values. 


\subsection{Viscosity}

The viscosity of hydrogels is a very significant feature for patient compliance, so the hydrogel is given for oral mucosa and local application should not be too fluid. A low viscosity product may spread in the application area and leak out. Too high viscosity can cause application difficulties [52]. Different viscosity values were presented in Table 3. In general, CP polymers are polymers of acrylic acid, crosslinked with polyalkenyl ethers or divinyl glycol. In several experiments, their neutralized aqueous dispersions demonstrated a high viscosity. It was found that a $\mathrm{pH}$ range of 5.0-9.0 usually leads to the formation of highly viscous systems [53]. In a study, the increase of $\mathrm{pH}$ in various concentrations of CP gels showed increased viscosity. Also, $\mathrm{CP}$ gels showed the highest viscosity when neutralized to $\mathrm{pH}$ 6.0 [54]. Because of these reasons, F3/F6 had the highest viscosity (the reason is the highest and alkaline $\mathrm{pH}$ value that comes from the polymer of $\mathrm{Na}-\mathrm{CMC}$ ) in our study. On the other hand, the viscosity of F4 was found to be very low. Şenyiğit et al. has reported that the viscosity of hydrogels increased as polymer concentration increased [41]. In our study, as the polymer concentration increases, the viscosity found high, as expected. When Arpa et al. compared gels containing $\mathrm{CP}$ and $\mathrm{Na}-\mathrm{CMC}$ in the same ratio, they found that the viscosity of hydrogels containing $\mathrm{CP}$ was higher [31]. Similarly, in our study, CP hydrogels (F1 and F2) showed higher viscosity values when compared to $\mathrm{Na}-\mathrm{CMC}$ hydrogels (F4 and F5). Based on the viscosity and visual assessment, Gull et al. concluded that the hydrogel prepared with $1.0 \% \mathrm{w} / \mathrm{w}$ CP 940 (4412 cP) was less viscous to be called a gel, and hydrogel prepared with $2.0 \% \mathrm{w} / \mathrm{w}$ CP 940 $(28197 \mathrm{cP})$ was a stiff gel which can create a problem during the topical application and handling. Hence, these two formulations were not considered for further studies and they selected hydrogel prepared with 1.5\% w/w CP 940 (14097 cP) [55]. Similarly, in our study F1, F4, F5, and F1/F4 were less viscous to be called a gel. F3/F6 was a stiff gel that can create a problem during the application and handling. So, we selected F2, F3, F6, and F2/F5 due to their better viscosity values.

Table 3. Viscosity values of the hydrogels and their blends

\begin{tabular}{lc}
\hline Code & Viscosity (cP) \\
\hline F1 & $4670 \pm 310$ \\
F2 & $10647 \pm 255$ \\
F3 & $15157 \pm 692$ \\
F4 & $444.8 \pm 11.5$ \\
F5 & $4272 \pm 40$ \\
F6 & $19087 \pm 51$ \\
F1/F4 (50/50) & $1056 \pm 62$ \\
F2/F5 (50/50) & $13305 \pm 1209$ \\
F3/F6 (50/50) & $138667 \pm 1858$ \\
\hline
\end{tabular}

\subsection{Mechanical Properties}

The mechanical properties such as firmness (hardness), consistency, cohesiveness, and work of cohesion of gels that contain different ratios of $\mathrm{CP} 934$ and Na-CMC were examined in this study. Mechanical parameters in texture studies are known to provide information on the performance of hydrogel formulations and have been used to identify formulations that may be suitable for applications. Texture analyses provide knowledge on transferring or applying the semi-solid formulations from the measured parameters of a pharmaceutical formulation [56].

The amount of gelling agent in a formulation is extremely important for its textural properties [57]. Gel firmness, which expresses the applicability of the gels to the skin, is directly correlated to the polymer concentration [57]. Hydrogels should possess specific mechanical properties since they should easily apply to the administration site, remain in the tissue for the desired time, and be easily removed from the package. Subsequently, mechanical testing properties should be evaluated. Table 4 summarizes the mechanical properties of hydrogels. The difference is very rational given that $\mathrm{CP}$ has been reported to produce firm hydrogels [58]. The firmness and consistency of $\mathrm{CP}$ and $\mathrm{Na}-\mathrm{CMC}$ hydrogels seem to increase with increasing polymer concentration. Similarly, Yang et al., Cevher et al., and Arpa et al. found an increase in gel firmness by increasing Carbopol concentration [31,57,59]. Also, the firmness values of the $\mathrm{Na}$ -CMC gels prepared by Jones et al. and Arpa et al. increased as the Na-CMC concentration increased $[31,60]$. Also, the formulations consisted of Carbopol (F1, F2, F3) exhibited a higher firmness value than the formulations based on $\mathrm{Na}-$ CMC (F4, F5, F6). Consequently, blending CP hydrogels with $\mathrm{Na}-\mathrm{CMC}$ can improve the low firmness values of $\mathrm{Na}$ CMC hydrogels. Similar to our study, the firmness of the formulation containing Carbopol was found higher than the formulation containing the same proportion of $\mathrm{CMC}$ in previous studies $[31,61]$. Besides, it has been claimed that the firmness values of $\mathrm{Na}-\mathrm{CMC}$ hydrogels are enhanced by enhancing carboxymethyl substitution, molecular weight, and polymer concentration [62]. For this reason, F6 is the firmest amongst F4, F5, and F6. Also, Abouhussein et al. reported that an increase in consistency for gels prepared at higher concentrations of $\mathrm{CP}$ and $\mathrm{Na}-\mathrm{CMC}$ and the consistency value higher in gels containing $\mathrm{CP}$ than gels containing $\mathrm{Na}-\mathrm{CMC}$ at the same rate, similarly to our study [63]. Similarly, one study found that the consistency of the formulation containing $\mathrm{CP}$ was higher than the formulation containing the same proportion of Na-CMC [64]. Cohesiveness and work of cohesion of $\mathrm{CP}$ and Na-CMC hydrogels seem to decrease with increasing polymer concentration. Cohesiveness is expressed as the structural reconstitution of the gel after application. If the gel-forming polymers are capable of attracting their molecules, they show high cohesiveness values [40]. According to the results of the studies, it was found that the cohesiveness values of the hydrogels decreased by increasing polymer concentration. Similarly, Cevher et al. and Tan et al. reported a reduction in gel cohesiveness for CP gels with increasing concentration of the polymers $[59,65]$. The adhesive properties of the polymers used in the preparation of gels are of great importance in this respect. It was concluded that as the polymer concentration increased, the adhesive properties of the gels increased $[40,41,66]$. In general, it has been observed that the work of cohesion value increases as the concentration of polymers increases.

Firmness is the maximum positive force required to attain a given deformation [67]. It introduces the necessary force to 
Table 4. Mechanical properties of hydrogels

\begin{tabular}{lcccc}
\hline Code & $\begin{array}{c}\text { Firmness } \\
\text { (g.Force) } \pm \text { SD }\end{array}$ & $\begin{array}{c}\text { Consistency } \\
\text { (g.sec) } \pm \text { SD }\end{array}$ & $\begin{array}{c}\text { Cohesiveness } \\
\text { (g) } \pm \text { SD }\end{array}$ & $\begin{array}{c}\text { Work of Cohesion } \\
\text { (g.sec) } \pm \text { SD }\end{array}$ \\
\hline F1 & $112.33 \pm 3.25$ & $854.62 \pm 5.92$ & $-72.48 \pm 4.16$ & $-590.65 \pm 14.27$ \\
F2 & $262.41 \pm 10.63$ & $1715.54 \pm 158.58$ & $-160.65 \pm 11.00$ & $-1041.73 \pm 69.88$ \\
F3 & $335.10 \pm 9.06$ & $2457.13 \pm 143.48$ & $-220.52 \pm 2.45$ & $-1518.12 \pm 128.15$ \\
F4 & $15.54 \pm 0.01$ & $186.69 \pm 4.64$ & $-11.93 \pm 0.15$ & $-15.04 \pm 0.68$ \\
F5 & $21.71 \pm 0.03$ & $196.63 \pm 0.46$ & $-17.13 \pm 0.02$ & $-38.11 \pm 0.57$ \\
F6 & $48.05 \pm 0.93$ & $429.61 \pm 6.10$ & $-33.33 \pm 0.41$ & $-410.98 \pm 6.67$ \\
F1/F4 (50/50) & $19.19 \pm 0.14$ & $187.42 \pm 0.81$ & $-15.38 \pm 0.19$ & $-28.56 \pm 0.96$ \\
F2/F5 (50/50) & $39.92 \pm 0.77$ & $356.27 \pm 9.01$ & $-28.58 \pm 0.81$ & $-231.31 \pm 15.02$ \\
F3/F6 (50/50) & $109.19 \pm 1.89$ & $891.32 \pm 7.12$ & $-61.64 \pm 0.86$ & $-728.78 \pm 9.03$ \\
\hline
\end{tabular}

ensure the formation of gels. It expresses the applicability of the gel to the desired site [40]. Firmness values should be low so that gel can be easily removed from the container and administrated to the skin surface easily $[56,59]$. The topical formulations should preferably have high consistency in the container but quickly pour or distribute during the application [68]. Hydrogel formulations are soft consistency and contain excess water [64]. Cohesiveness is described as the work required to deform the hydrogel in the downward movement of the probe [57]. It is a parameter related to the structural reformation following successive shearing stress during application [65]. It is the distance hydrogel travels before detachment [69]. Texture also provides an opinion on cohesiveness, which is a guess of the extent of structural reformation after the utilization of the formulation. Cohesiveness improves the performance of the formulation in the application area. Also, a lower cohesion value is preferred as it indicates that the formulation spreads [56]. If the hydrogel is extremely cohesive and hard, it will be difficult to apply to the skin surface [70]. The work of cohesion represents the work needed to overcome the internal bonds of the material [67]. Accordingly, F4 (15.54 \pm 0.01$),$ F5 (21.71 \pm 0.03$), \quad$ F6 (48.05 \pm 0.93$), \quad F 1 / F 4$ $(19.19 \pm 0.14)$, and F2/F5 (39.92 \pm 0.77$)$ have a low firmness value. Among them, F4 (186.69 \pm 4.64$)$, F5 (196.63 \pm 0.46$)$, F1/F4 (187.42 \pm 0.81$)$, and F2/F5 (356.27 \pm 9.01$)$ have a soft consistency. Also, F4 (-11.93 \pm 0.15$),$ F5 (-17.13 \pm 0.02$),$ F1/F4 $(-15.38 \pm 0.19)$, and F2/F5 $(-28.58 \pm 0.81)$ have low cohesion value that showed the formulation spreads.

\section{CONCLUSION}

Herein, hydrogel formulations were developed and studied for their mechanical properties so as their potential application for local delivery. Two biocompatible polymers, Carbopol and carboxymethyl cellulose were used from the preparation of the hydrogels. Apart from the pure hydrogels, blends of the Carbopol and carboxymethyl cellulose hydrogels were developed to obtain better physicochemical and mechanical properties. The preliminary results demonstrated that hydrogels can be used for oral mucosa and wound drug delivery in future studies. After all tests were completed, the F2/F5 formulation, $\mathrm{pH} \quad(5.86 \pm 0.084)$, viscosity (13305 \pm 1209$)$, firmness $(39.92 \pm 0.77)$, consistency (356.27 \pm 9.01$)$, cohesiveness $(-28.58 \pm 0.81)$, and work of cohesion $(-231.31 \pm 15.02)$ values were found to be the most suitable formulation.

\section{ACKNOWLEDGMENTS}

The authors are grateful to the University of Health Sciences Scientific Research Projects Coordination Unit (project number 2019/013) for obtaining the Texture Analyzer equipment used in this manuscript.

\section{CONFLICT OF INTEREST DECLARATION}

The authors report no conflict of interest. The authors alone are responsible for the content and the writing of the paper.

\section{FINANCIAL SUPPORT}

This research received no grant from any funding agency/ sector.

\section{AUTHOR IDs}

EÖB: Ece Özcan Bülbül

ORCID: 0000-0001-7112-923X

PIS: Panoraia I. Siafaka

ORCID: 0000-0001-7256-3230

GM: Gökçe Mutlu

ORCID: 0000-0002-0287-2588

NÜO: Neslihan Üstündağ Okur

ORCID: 0000-0002-3210-3747

\section{AUTHOR CONTRIBUTIONS}

Concept: PIS, NÜO; Design: EÖB, PIS, GM, NÜO; Supervision: PIS, NÜO; Materials: NÜO; Data Collection and/or Processing: EÖB, PIS, GM, NÜO; Analysis and/or Interpretation: EÖB, PIS, GM, NÜO; Literature Search: EÖB, PIS, GM, NÜO; Writing: EÖB, PIS, GM, NÜO; Critical Reviews: PIS, NÜO.

\section{REFERENCES}

[1] Li J, Mooney DJ. Designing hydrogels for controlled drug delivery. Nat Rev Mater. (2016); 1: 16071.

https://doi.org/10.1038/natrevmats.2016.71

[2] Paderni C, Compilato D, Giannola LI, Campisi G. Oral local drug delivery and new perspectives in oral drug formulation. Oral Surg Oral Med Oral Pathol Oral Radiol. (2012); 114: 25-34. https://doi.org/10.1016/j.oooo.2012.02.016

[3] Nguyen S, Hiorth M. Advanced drug delivery systems for local treatment of the oral cavity. Ther Deliv. (2015); 6: 595-608. https://doi.org/10.4155/tde. 15.5

[4] Öhnstedt E, Lofton Tomenius H, Vågesjö E, Phillipson M. The discovery and development of topical medicines for wound healing. Expert Opin Drug Discov. (2019); 14: 485-497. https://doi.org/10.1080/17460441.2019.1588879

[5] Minhas S, Sajjad A, Kashif M, Taj F, Alwadaani H, Khurshid Z. Oral ulcers presentation in systemic diseases: An update. Maced J Med Sci. 
(2019); 7: 3341-3347. https://doi.org/10.3889/oamjms.2019.689

[6] Leão JC, Gomes VB, Porter S. Ulcerative lesions of the mouth: an update for the general medical practitioner. Clinics. (2007); 62: 769780. https://doi.org/10.1590/S1807-59322007000600018

[7] Casamassimo PS, Flaitz CM, Hammersmith K, Sangvai S, Kumar A. Recognizing the relationship between disorders in the oral cavity and systemic disease. Pediatr Clin North Am. (2018); 65: 1007-1032. https://doi.org/10.1016/j.pcl.2018.05.009

[8] Karavana SY, Hokman Gökçe E, Rençber, Özbal S, Pekçetin C Güneri P, Ertan G. A new approach to the treatment of recurrent aphthous stomatitis with bioadhesive gels containing cyclosporine A solid lipid nanoparticles: in vivo/in vitro examinations. Int $J$ Nanomedicine. (2012); 7: 5693-5704. https://doi.org/10.2147/IJN.S36883

[9] Preeti L, Magesh K, Rajkumar K, Karthik R. Recurrent aphthous stomatitis. J Oral Maxillofac Pathol. (2011); 15: 252 https://doi.org/10.4103/0973-029X.86669

[10] Belenguer-Guallar I, Jiménez-Soriano Y, Claramunt-Lozano A Treatment of recurrent aphthous stomatitis. A literature review. J Clin Exp Dent. (2014); 6: 168-174

https://doi.org/10.4317/jced.51401

[11] Tarakji B, Gazal G, Al-Maweri SA, Azzeghaiby SN, Alaizari N. Guideline for the diagnosis and treatment of recurrent aphthous stomatitis for dental practitioners. J Int Oral Heal. (2015); 7: 74-80.

[12] Fiorillo L. Chlorhexidine gel use in the oral district: A systematic review. Gels. (2019); 5: 31. https://doi.org/10.3390/gels5020031

[13] Özcan Bülbül E, Mesut B, Cevher E, Öztaş E, Özsoy Y. Product transfer from lab-scale to pilot-scale of quetiapine fumarate orodispersible films using quality by design approach. J Drug Deliv Sci Technol. (2019); 54. https://doi.org/10.1016/j.jddst.2019.101358

[14] Garcia-Orue I, Pedraz JL, Hernandez RM, Igartua M Nanotechnology-based delivery systems to release growth factors and other endogenous molecules for chronic wound healing. J Drug Deliv Sci Technol. (2017); 42: 2-17. https://doi.org/10.1016/j.jddst.2017.03.002

[15] Siafaka PI, Zisi AP, Exindari MK, Karantas ID, Bikiaris DN. Porous dressings of modified chitosan with poly(2-hydroxyethyl acrylate) for topical wound delivery of levofloxacin. Carbohydr Polym. (2016); 143: 90-99. https://doi.org/10.1016/j.carbpol.2016.02.009

[16] Okur ME, Karantas ID, Şenyiğit Z, Okur NÜ, Siafaka PI. Recent trends on wound management; new therapeutic choices based on polymeric carriers. Asian J Pharm Sci. (2020); 15(6): 661-684. https://doi.org/10.1016/j.ajps.2019.11.008

[17] Rahim K, Saleha S, Zhu X, Huo L, Basit A, Franco OL. Bacterial contribution in chronicity of wounds. Microb Ecol. (2017); 73: 710 721. https://doi.org/10.1007/s00248-016-0867-9

[18] Fogh K, Nielsen J. Clinical utility of foam dressings in wound management: a review. Chronic Wound Care Manag Res. (2015); 2015(2): 31-38. https://doi.org/10.2147/CWCMR.S50832

[19] Shi C, Wang C, Liu H, Li Q, Li R, Zhang Y, Liu Y, Shao Y, Wang J. Selection of appropriate wound dressing for various wounds. Front Bioeng Biotechnol. (2020); 8: 1-17. https://doi.org/10.3389/fbioe.2020.00182

[20] Dhivya S, Padma VV, Santhini E. Wound dressings - a review. BioMedicine. (2015); 5(4): 22. https://doi.org/10.7603/s40681-015-0022-9

[21] Rezvani Ghomi E, Khalili S, Nouri Khorasani S, Esmaeely Neisiany R, Ramakrishna S. Wound dressings: Current advances and future directions. J Appl Polym Sci. (2019); 136: 1-12. https://doi.org/10.1002/app.47738

22] Tavakoli S, Klar AS. Advanced hydrogels as wound dressings. Biomolecules. (2020); 10(8): 1169. https://doi.org/10.3390/biom10081169

[23] Kamoun EA, Kenawy ERS, Chen X. A review on polymeric hydrogel membranes for wound dressing applications: PVA-based hydrogel dressings. J Adv Res. (2017); 8(3): 217-233. https://doi.org/10.1016/j.jare.2017.01.005

[24] Kim MH, Park H, Nam HC, Park SR, Jung JY, Park WH. Injectable methylcellulose hydrogel containing silver oxide nanoparticles for burn wound healing. Carbohydr Polym. (2018); 181: 579-586. https://doi.org/10.1016/j.carbpol.2017.11.109

[25] Üstündağ Okur N, Hökenek N, Okur ME, Ayla S, Yoltaş A, Siafaka PI, Cevher E. An alternative approach to wound healing field; new composite films from natural polymers for mupirocin dermal delivery. Saudi Pharm J. (2019); 27(5): 738-752. https://doi.org/10.1016/j.jsps.2019.04.010

[26] Sharpe LA, Daily AM, Horava SD, Peppas NA. Therapeutic applications of hydrogels in oral drug delivery. Expert Opin Drug Deliv. (2014); 11(6): 901-915. https://doi.org/10.1517/17425247.2014.902047

[27] Bahram M, Mohseni N, Moghtader M. An Introduction to Hydrogels and Some Recent Applications. Emerg. Concepts Anal Appl Hydrogels, InTech. (2016). https://doi.org/10.5772/64301

[28] Üstündağ Okur N, Yağcilar AP, Siafaka PI. Promising polymeric drug carriers for local delivery; the case of in situ gels. Curr Drug Deliv. (2020); 17(8): 675-693. https://doi.org/10.2174/1567201817666200608145748

[29] Chang FC, Tsao CT, Lin A, Zhang M, Levengood SL, Zhang M. PEG -chitosan hydrogel with tunable stiffness for study of drug response of breast cancer cells. Polymers. (2016); 8(4): 1-13.

https://doi.org/10.3390/polym8040112

[30] Thangavel P, Ramachandran B, Kannan R, Muthuvijayan V. Biomimetic hydrogel loaded with silk and 1-proline for tissue engineering and wound healing applications. J Biomed Mater Res Part B Appl Biomater. (2017); 105(6): 1401-1408. https://doi.org/10.1002/jbm.b.33675

[31] Arpa MD, Yoltaş A, Onay Tarlan E, Şahin Şenyüz C, Sipahi H, Aydın A, Üstündağ Okur N. New therapeutic system based on hydrogels for vaginal candidiasis management: formulationcharacterization, antibacterial activity, vaginal irritation and direct contact test. Pharm Dev Technol. (2020); 10: 1-33. https://doi.org/10.1080/10837450.2020.1809457

[32] R. Varges P, M. Costa C, S. Fonseca B, F. Naccache M, De Souza Mendes P. Rheological characterization of Carbopol ${ }^{\circledR}$ dispersions in water and in water/glycerol solutions. Fluids. (2019); 4(1): 3. https://doi.org/10.3390/fluids4010003

[33] Singla AK, Chawla M, Singh A. Potential applications of carbomer in oral mucoadhesive controlled drug delivery system: A review. Drug Dev Ind Pharm. (2000); 26(9): 913-924. https://doi.org/10.1081/DDC-100101318

[34] Chen X, Yan J, Yu S, Wang P. Formulation and in vitro release kinetics of mucoadhesive blend gels containing matrine for buccal administration. AAPS PharmSciTech. (2018); 19: 470-480. https://doi.org/10.1208/s12249-017-0853-7

[35] Ergun R, Guo J, Huebner-Keese B. Cellulose. Encycl Food Heal. Elsevier; (2016), p. 694-702 https://doi.org/10.1016/B978-0-12-384947-2.00127-6

[36] Aravamudhan A, Ramos DM, Nada AA, Kumbar SG. Natural Polymers. Nat Synth Biomed Polym. Elsevier; (2014), p. 67-89. https://doi.org/10.1016/B978-0-12-396983-5.00004-1

[37] Bayindir Bilgic M, Lacin NT, Berber H, Mansuroglu B. In vitro evaluation of alpha-tocopherol loaded carboxymethylcellulose chitosan copolymers as wound dressing materials. Mater Technol (2019); 34(7): 386-393 https://doi.org/10.1080/10667857.2019.1573944

[38] Hanna DH, Lotfy VF, Basta AH, Saad GR. Comparative evaluation for controlling release of niacin from protein- and cellulose-chitosan based hydrogels. Int J Biol Macromol. (2020); 150: 228-237. https://doi.org/10.1016/j.ijbiomac.2020.02.056

[39] Chandra M V., Shamasundar BA. Texture profile analysis and functional properties of gelatin from the skin of three species of fresh water fish. Int J Food Prop. (2015); 18(3): 572-584. https://doi.org/10.1080/10942912.2013.845787

[40] Cevher E, Sensoy D, Taha MAM, Araman A. Effect of thiolated polymers to textural and mucoadhesive properties of vaginal gel formulations prepared with polycarbophil and chitosan. AAPS PharmSciTech. (2008); 9: 953-965. https://doi.org/10.1208/s12249-008-9132-y

[41] Senyiğit ZA, Karavana SY, Eraç B, Gürsel Ö, Limoncu MH, Baloğlu E. Evaluation of chitosan based vaginal bioadhesive gel formulations for antifungal drugs. Acta Pharm. (2014); 64(2): 139-156 https://doi.org/10.2478/acph-2014-0013

[42] Andrews GP, Laverty TP, Jones DS. Mucoadhesive polymeric platforms for controlled drug delivery. Eur J Pharm Biopharm. (2009); 71(3): 505-518. https://doi.org/10.1016/j.ejpb.2008.09.028

[43] Mansuri S, Kesharwani P, Jain K, Tekade RK, Jain NK. Mucoadhesion: A promising approach in drug delivery system. React Funct Polym. (2016); 100: 151-172. https://doi.org/10.1016/j.reactfunctpolym.2016.01.011

44] Başaran B, Bozkir A. Thermosensitive and $\mathrm{pH}$ induced in situ ophthalmic gelling system for ciprofloxacin hydrochloride: Hydroxypropyl- $\beta$-cyclodextrin complex. Acta Pol Pharm. (2012); 69 (6): 1137-1147.

[45] Riaz T, Zeeshan R, Zarif F, Ilyas K, Muhammad N, Safi SZ, Rahim A, Rizvi SAA, Rehman IU. FTIR analysis of natural and synthetic collagen. Appl Spectrosc Rev. (2018); 53(9): 703-746. https://doi.org/10.1080/05704928.2018.1426595

46] Üstündağ Okur N, Filippousi M, Okur ME, Ayla Ș, Cağlar EŞ, Yoltaş A, Siafaka PI. A novel approach for skin infections: Controlled release topical mats of poly(lactic acid)/poly(ethylene succinate) blends containing Voriconazole. J Drug Deliv Sci Technol. (2018); 46:74-86. https://doi.org/10.1016/j.jddst.2018.05.005 
[47] Siafaka PI, Barmbalexis P, Bikiaris DN. Novel electrospun nanofibrous matrices prepared from poly(lactic acid)/poly(butylene adipate) blends for controlled release formulations of an antirheumatoid agent. Eur J Pharm Sci. (2016); 88: 12-25.

https://doi.org/10.1016/j.ejps.2016.03.021

[48] Fan H, Zhang P, Zhou L, Mo F, Jin Z, Ma J, et al. Naringin-loaded polymeric micelles as buccal tablets: formulation, characterization, in vitro release, cytotoxicity and histopathology studies. Pharm Dev Technol. (2020); 25(5): 547-555.

https://doi.org/10.1080/10837450.2020.1715427

[49] Németh C, Gyarmati B, Gacs J, Salakhieva D V., Molnár K, Abdullin T, Laszlo K, Szilagyi A. Fast dissolving nanofibrous matrices prepared by electrospinning of polyaspartamides. Eur Polym J. (2020); 130: 109624. https://doi.org/10.1016/j.eurpolymj.2020.109624

[50] Dong P, Sahle FF, Lohan SB, Saeidpour S, Albrecht S, Teutloff C, Bodmeier R, Unbehauen M, Wolff C, Hagg R, Lademann J, Patzelt A, Schafer-Korting M, Meinle MC. pH-sensitive Eudragit ${ }^{\circledR}$ L 100 nanoparticles promote cutaneous penetration and drug release on the skin. J Control Release. (2019); 295: 214-222. https://doi.org/10.1016/j.jconrel.2018.12.045

[51] Kocic H, Stankovic M, Tirant M, Lotti T, Arsic I. Favorable effect of creams with skimmed donkey milk encapsulated in nanoliposomes on skin physiology. Dermatol Ther. (2020); 33(4): 1-7. https://doi.org/10.1111/dth.13511

[52] Patel P, Patel P. Formulation and evaluation of clindamycin HCL in situ gel for vaginal application. Int J Pharm Investig. (2015); 5(1): 5056. https://doi.org/10.4103/2230-973x.147233

[53] Abdullah GZ, Abdulkarim MF, Mallikarjun C, Mahdi ES, Masri M, Sattar MA, Noor AM. Carbopol 934, 940 and Ultrez 10 as viscosity modifiers of palm olein esters based nano-scaled emulsion containing ibuprofen. Pak J Pharm Sci. (2013); 26(1): 75-83.

[54] Shin SC, Kim JY, Oh IJ. Mucoadhesive and physicochemical characterization of carbopol-poloxamer gels containing triamcinolon acetonide. Drug Dev Ind Pharm. (2000); 26(3): 307-312. https://doi.org/10.1081/ddc-100100358

[55] Gull A, Ahmed S, Jalees F, Nagaich U, Chandra A. Hydrogel thickened microemulsion; a local cargo for the co- delivery of cinnamaldehyde and berberine to treat acne vulgaris. J Drug Deliv Sci Technol. (2020); 58: 101835. https://doi.org/10.1016/j.jddst.2020.101835

[56] Amasya G, Inal O, Sengel-turk CT. SLN enriched hydrogels for dermal application: Full factorial design study to estimate the relationship between composition and mechanical properties. Chem Phys Lipids. (2020); 228: 104889. https://doi.org/10.1016/j.chemphyslip.2020.104889

[57] Yang Z, Peng H, Wang W, Liu T. Crystallization behavior of poly( $\varepsilon-$ caprolactone)/layered double hydroxide nanocomposites. J Appl Polym Sci. (2010); 116(5): 2658-2667. https://doi.org/10.1002/app.31787

[58] Marques AC, Rocha AI, Leal P, Estanqueiro M, Lobo JMS Development and characterization of mucoadhesive buccal gels containing lipid nanoparticles of ibuprofen. Int J Pharm. (2017); 533 (2): 455-462. https://doi.org/10.1016/j.ijpharm.2017.04.025
[59] Cevher E, Taha MAM, Orlu M, Araman A. Evaluation of mechanical and mucoadhesive properties of clomiphene citrate gel formulations containing carbomers and their thiolated derivates. Drug Deliv. (2008); 15(1): 57-67. https://doi.org/10.1080/10717540701829234

[60] Jones DS, Woolfson AD, Brown AF. Textural, viscoelastic and mucoadhesive properties of pharmaceutical gels composed of cellulose polymers. Int J Pharm. (1997); 151(2): 223-233. https://doi.org/10.1016/S0378-5173(97)04904-1

[61] Nep EI, Conway BR. Grewia gum 2: mucoadhesive properties of compacts and gels. Trop J Pharm Res. (2011) ;10(4): 393-401. https://doi.org/10.4314/tjpr.v10i4.4

62] Vlaia L, Coneac G, Olariu I, Vlaia V, Lupuleasa D. Cellulosederivatives-based hydrogels as vehicles for dermal and transdermal drug delivery. Emerg Concepts Anal Appl Hydrogels, InTech; (2016). https://doi.org/10.5772/63953

[63] Abouhussein DMN, Khattab A, Bayoumi NA, Mahmoud AF, Sakr TM. Brain targeted rivastigmine mucoadhesive thermosensitive In situ gel: Optimization, in vitro evaluation, radiolabeling, in vivo pharmacokinetics and biodistribution. J Drug Deliv Sci Technol. (2018); 43: 129-140. https://doi.org/10.1016/j.jddst.2017.09.021

[64] Hosary ER, El-Mancy SMS, Deeb KS, Eid HH, Tantawy ME EL, Shams MM, Samir R, Assar NH, Sleem AA. Efficient wound healing composite hydrogel using Egyptian Avena sativa L. polysaccharide containing $\beta$-glucan. Int J Biol Macromol. (2020); 149: 1331-1338. https://doi.org/10.1016/j.ijbiomac.2019.11.046

[65] Tan YTF, Peh KK, Al-Hanbali O. Effect of carbopol and polyvinylpyrrolidone on the mechanical, rheological, and release properties of bioadhesive polyethylene glycol gels. AAPS PharmSciTech. (2000); 1: 69-78. https://doi.org/10.1208/pt010324

[66] Hurler J, Engesland A, Poorahmary Kermany B, Škalko-Basnet N. Improved texture analysis for hydrogel characterization: $\mathrm{Gel}$ cohesiveness, adhesiveness, and hardness. J Appl Polym Sci. (2012); 125(1): 180-188. https://doi.org/10.1002/app.35414

[67] Coviello T, Trotta AM, Marianecci C, Carafa M, Di Marzio L, Rinaldi F, Meo CD, Alhaique F, Matricardi P. Gel-embedded niosomes: preparation, characterization and release studies of a new system for topical drug delivery. Colloids Surfaces B Biointerfaces. (2015); 125(1): 291-299. https://doi.org/10.1016/j.colsurfb.2014.10.060

[68] Algahtani MS, Ahmad MZ, Ahmad J. Nanoemulsion loaded polymeric hydrogel for topical delivery of curcumin in psoriasis. $J$ Drug Deliv Sci Technol. (2020); 59: 101847. https://doi.org/10.1016/j.jddst.2020.101847

[69] Singh B, Sharma S, Dhiman A. Design of antibiotic containing hydrogel wound dressings: Biomedical properties and histological study of wound healing. Int J Pharm. (2013); 457(1): 82-91. https://doi.org/10.1016/j.ijpharm.2013.09.028

[70] Li H, Jia Y, Liu C. Biointerfaces Pluronic ${ }^{\circledR}$ F127 stabilized reduced graphene oxide hydrogel for transdermal delivery of ondansetron : ex vivo and animal studies. Colloids Surfaces B Biointerfaces. (2020); 195: 111259. https://doi.org/10.1016/j.colsurfb.2020.111259 